\section{Allergy $_{\mathrm{and}}$ \\ Immunology}

Andritschke, K. 17

Aygören-Pürsün, E. 21

Bethune, C. 10

Boccon-Gibod, I. 10

Bork, K. 10

Bouillet, L. 21

Boysen, H.B. 21

Caballero, T. 10

Cancian, M. 10

Cicardi, M. 3

Craig, T.J. 1 , 3 , 10,26
Hébert, J. 3

Keith, P.K. 10

Longhurst, H.J. 3

Magerl, M. 17

Martinez-Saguer, I. 3

Neri, S. 10

Rossi, O. 17

Sala-Cunill, A. 10

Symons, C. 17

\title{
Subject Index Vol. 161, Suppl. 1, 2013
}

Barriers 21

Benefits 10

Challenges 21

Consensus 3

Current status 10

Guidelines 3
Hereditary angioedema 3, 10, 17, 21

Practicalities 17

Quality of life 10, 21

Self-administration $3,10,17,21$ 